\title{
The Panopticon and the Performance Arena: HCI Reaches within
}

\author{
Ann Light and Peter Wright \\ Sheffield Hallam University, Sheffield, S1 1WB

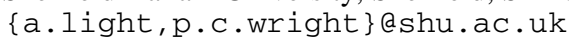

\begin{abstract}
The impact of new technologies is hard to predict. We suggest the value of theories of performativity in understanding dynamics around the convergence of biomedical and information technology. Drawing on the ideas of Butler and Foucault, we discuss a new, internal, context for HCI and raise potentially disturbing issues with monitoring health. We argue that by adopting explicitly social framings we can see beyond the idea of medical interventions to tools for wellbeing and recognize more of the implications of looking within.
\end{abstract}

Keywords: performativity, bodies, embodiment, biomedical, convergence.

\section{Introduction}

Research is being conducted on wellbeing and healthcare to provide new interfaces with the body (eg [1]), such as sensors and monitors. Although much work has been focused on the ethics and the practicalities of privacy in medical contexts, such as data protection for patient records [2], there has been less consideration of sociopolitical issues such as the effects of living wired up to the local medical centre. Rodden notably quipped during a keynote vision of the future [3] that he didn't want a fridge conspiring with his kids to stop him having a beer because his blood sugar was high. Awareness of health, with the attendant expectation that one will look after it, might seem an incontrovertible good, but carries with it the seeds of new normative behaviors with socio-political potentials. The complex relation between the human body (particularly its internal function) and such socio-political behaviors are difficult to articulate within our traditional conceptions of humans as technology users. In this paper, we engage theories of performativity [4] as a way of articulating these relations. And we open a space to discuss whether we can explore engagement with bodily practices fruitfully by seeing them as a performance for self and others.

To set the scene for this discussion, we identify the following developments:

- Networked/ubiquitous computing: the means of joining together information from different sources, transmitting it and using it differentially.

- Processing power for data mining: extracting specified information (such as heart rate, brain waves and gastric processing) from vast reserves.

- Nanotechnology: intervention on a scale that allows new sites of monitoring, particularly of the internal human state through implantation.

- Advances in Genetic Science including the human genome project: giving rise to new understandings of causal relations (like disease and genetic coding) and genetic difference across race and gender. 


\subsection{Performance and Identity}

Performance has been used to understand interaction in many ways. There is the use of actual performances or methods drawn from drama (eg [5],[6]), but this does not concern us here. Another strand has used performance as a metaphor for people's engagement with technology ([7], [8]). HCI has drawn from Goffman [9] (eg [10]) for insights into how people construct their relations with others and more specifically how they present themselves. For instance, they may perceive themselves to be backor front-stage in the company of others, and we can observe that most people feel the insides of their bodies should be backstage, ie a topic only for those they know and trust. Healey and Light make a crucial distinction between 'performing' as the designer of a tool intended and the potential appropriation of the tool for performing as social display [7]. Both they and [8] give the example of Dance Dance Revolution (DDR). DDR is not used as conceived because the shared aesthetics of dancing in public was overlooked in the design. Consequently, features are used in unanticipated ways for acquiring social standing. In reflecting upon the social engagement around the tool, [7] look beyond a common use of performance for exploring human-machine relations and implicitly consider the related area of performativity, or the creation of identity through repeated enactment [4]. "One is not simply a body, but, in some very key sense, one does one's body and, indeed, one does one's body differently from one's contemporaries" [4:272]. To date, most performance of identity is outside the $\operatorname{skin}^{1}$. Here we wish to go further, beyond the traditional arenas for 'doing one's body', to consider what happens when monitors and sensors turn identity inside out and give us access to 'do' one's body publicly from within. We invoke performance arenas - and the panopticon - to look at the effect of internal monitoring on identity.

\section{Performing as a Healthy Being}

One feature of Butler's analysis of how identity (for her, specifically gender) becomes created is the way that it is reinforced by social norms. This has a correlation in medical contexts. In treating conditions such as diabetes, the uses of automatic devices which monitor and inject insulin unquestionably provide support and safety, and may save lives. What happens, though, when such devices routinely report on the body's condition, either to the person or to professionals? Whose knowledge is it that a run of fish and chips has affected insulin levels? How does public health policy interact with people's choices about lifestyle? We must ask if the monitored person has the 'right' to live badly in the eyes of the wider populace and whether 'bad' behavior should affect access to treatment or the cost of life insurance. We could argue that, designed in or not, health gadgets persuade (take your tablets; eat less fat). Just as the wattson [11] makes one aware of use of fuel, so body monitoring can lead to societal pressures akin to those toward green living.

Foucault [12], in his analysis of power relations, suggests mere awareness that a controlling agent might be monitoring everyone at all times promotes individuals' compliance with the rules of the system. He conceives of this in a public world with

\footnotetext{
${ }^{1}$ Though let us note work, primarily in art, where internal modifications are manifested outwardly (eg [13]) and literature on the Cyborg (eg [14]).
} 
centrally located viewing posts that, in turn, those monitored can see. By putting human-technology interfaces into the body, we are led to consider how previously hidden aspects of a person are made available and to whom. By likening the introduction of observation technologies to this panopticon, we highlight both the new arena for inspection these tools introduce and the performative attributes of internal readings, thereby raising the issue of conformity. In taking this perspective, questions arise which reach beyond intervention, safety and privacy, to consider understandings of observation and agency, such as:

- Who is the audience for an internal view of what my body does?

- How do I want to portray myself and what scope exists to choose a portrayal?

- Am I empowered to resist others' readings of my condition?

- What is the impact of my new visibility upon my sense of self and wellbeing?

\subsection{Performing in Networks Where Machines Watch over Us}

So who is looking into our bodies? In the networked world, the performance of health may be interpreted by society, but its first audience is machines with capacity to make connections between streams of data, note intersections and store patterns. In other words, this audience is forming judgments about the nature of the individual. But, whereas when I dance, how I dance and what I wear are all familiar choices that I make in using DDR, I have less awareness about or creativity in how I 'do' my body. We can reflect that, as audience, a machine is impersonal and apparently apolitical in the face of my body's performance: a machine does not process identity based on appearance and other qualitative aspects, but finds rationale in metrics. However, ostensibly neutral quantitative approaches operate with embedded political readings of information and how it should be manipulated. For instance, statistical genetic information will be more interesting to a machine than skin color. But the use of statistical genetic data relating to race will, in itself, be politically charged, as will any embedded interpretative formulae used in analytic systems. What kind of body would a person want to 'do' in this context? It is not easy to predict, even if a warning about sickle cell anaemia would be useful, but asking brings us closer to an answer. What sort of audience do we want to construct? Reflective? Empathetic? One sharing embedded co-experiences? Or is that to mislead people with a 'kind' front-end?

\section{Discussion}

We have presented a developing trend in mediation and a way of framing it so that the implications can be seen in social terms. By calling on an (inter)active reading of the construction of identity and its relation to changes in biomedical practices, we offer a demonstration of how medical interfaces can affect public aesthetics. Just as DDR was not conceived to be about performing socially, neither are the tools here and yet we see that they offer this opportunity. However, whereas the dancers using DDR can choose a public image to 'do' even if they cannot choose their spectators, the panopticon is imposed from outside into a space where we are genetically programmed and have less recourse to (re)inventing ourselves. It is an arena in which we are not used to appearing and have little understanding of presentation. 
We offer a distinction, and it is subtle, between wellbeing tools and health tools. In designing health interventions, is our highest purpose to support individual wellbeing? (Instead, it may be to keep welfare costs down.) People's greatest good may not be served by the pressure to conform in yet another arena: anxiety about obesity may not be its best cure. So we suggest the device of exploring implanted and embodied health technology through performativity to encourage new discourses around presentation and control. Such measures will be critical if we are not thoughtlessly to embed new orthodoxies of behavior in the code of our creations. We offer this analysis as providing an opportunity to design tools - and connections between them - that allow people to perform themselves inside and out with discretion, decorum and control.

\section{References}

1. Leonhardt, S.: Personal Healthcare Devices. In: Mukherjee, S., Aarts, R.R., Widdershoven, F., Ouwerkerk, M. (eds.) amIware Hardware Techbology Drivers of Ambient Intelligence, part. 6, Springer, Heidelberg (2006)

2. Brown, I., Adams, A.A.: The ethical challenges of ubiquitous healthcare. Int. Review of Information Ethics 8, 53-60 (2007)

3. Rodden, T.: Ubiquitous computing in the real world. In: HCI 2006 Keynote address (2006)

4. Butler, J.: Performative Acts and Gender Constitution: An Essay in Phenomenology and Feminist Theory. In: Case, S. (ed.) Performing Feminisms: Feminist Critical Theory and Theatre. Johns Hopkins UP, Baltimore (1990)

5. Newell, A.F., Morgan, M.E., Gregor, P., Carmichael, A.: Theatre as an intermediary between users and CHI designers. In: Proc. CHI 2006 (2006)

6. Light, A., Weaver, L., Healey, P.G., Simpson, G.: Adventures in the Not Quite Yet: using performance techniques to raise design awareness about digital networks. In: Proc. DRS (2008)

7. Healey, P.G., Light, A.: When Scoring doesn't Matter: The aesthetics of performance in arcade games. Co Design suppl. 1 (2007)

8. Dalsgaard, P., Hansen, L.K.: Performing Perception-Staging Aesthetics of Interaction. ToCHI 15(3), 1-33 (2008)

9. Goffman, E.: The Presentation of Self in Everyday Life. Penguin Books $(1959,1990)$

10. Hulme, M., Truch, A.: The role of interspace in sustaining identity. In: Glotz, P., Bertschi, S., Locke, C. (eds.) Thumb Culture: The Meaning of Mobile Phones for Society, pp. 137148. Transcript Verlag, Bielefeld (2005)

11. Wattson, http://www. diykyoto.com/uk

12. Foucault, M.: Discipline and Punish: the Birth of the Prison. Random House, New York (1975)

13. Stelarc, http://www.stelarc.va.com.au/

14. Haraway, D.A.: Cyborg Manifesto. In: Simians, Cyborgs and Women: The Reinvention of Nature, pp. 149-181. Routledge, New York (1991) 